\title{
Bisexualidades feministas. Contra-relatos desde una disidencia situada
}

\author{
Laura Arnés, Malena Correa, Agustina Herrero, Agostina Invernizzi, Josefina Itoiz, Iris Luz Ortellao \\ y Ayelén Pandolfi Chediac (eds.) (2019) \\ Buenos Aires, Madreselva , 256 pp.
}

\section{- Sofía B. Lamarca \\ Instituto de Filología y literaturas Hispánicas Amado Alonso UBA}

Bisexualidades feministas. Contra-relatos desde una disidencia situada se presenta, en principio, desde la multiplicidad. Diversidad de autorxs, gestos y posicionamientos integran la propuesta inicial de este conjunto de textos que irrumpe de manera necesaria en una escena política y de construcción teórica preocupada por la sexualidad desobediente y las jerarquizaciones, polémicas y hasta invisibilizaciones que se albergan en el uso de la palabra disidencia. En este sentido, el recorrido por los distintos artículos y relatos ponen en evidencia que el propósito es el de precisar una existencia, un modo de habitar el mundo y de generar conocimiento desde la bisexualidad. Desde lo múltiple, también, es que el libro completa su configuración a partir de la primera presentación. Considero necesario registrar el escenario para una lectura crítica ya que forma parte de las decisiones de las editoras y compiladoras que conforman un posicionamiento político y estético ante el imprevisto. Casa Brandon, bastión de la resistencia para los sectores de la disidencia, colmó su capacidad y una gran cantidad de personas - casi la misma que estaba dentro del centro cultural-quedó afuera, literalmente, de la presentación. Sin embargo, no fue de esa manera en rigor. Las bisexuales feministas no "dejaron afuera" a nadie y desdoblaron y bifurcaron la presentación del libro, replicando en la vereda las intervenciones que sucedían adentro. Aquello que podría haber sido un incidente se convirtió en una posibilidad de multiplicar, ampliar e incluir, y es también una puerta de entrada a los textos reunidos en esta obra.

El libro se estructura de manera novedosa, al menos para el ámbito de las publicaciones académicas, y es funcional también a lo que propone su irrupción: abandonar lo unidireccional, la única posibilidad, para bifurcarse, y apostar tanto a la rigurosidad teórica como a la valoración de las propias experiencias enraizadas. Así, como afirma su subtítulo, se sitúa en este rincón del mundo, apelando a las diversas trayectorias militantes, académicas y afectivas. Como un acento en la intención de poner en valor la experiencia vital y militante como modo de conocer y nombrar una existencia, el anexo de registros visuales permite ubicar las derivas del activismo y las vidas bisexuales desde sus expresiones en el campo de lo público, y las posibilidades del deseo y el afecto dentro de esos circuitos. Es en esta línea que la identidad bisexual intersecciona con el reconocimiento como feministas, y el movimiento político e identitario se complejiza, permitiendo una ampliación en las categorías de análisis y también en la percepción de la experiencia.

De esta manera, la primera parte "Lo bisexual en cuestión: modulaciones entre la teoría y el activismo" reúne una serie de artículos que intentan conceptualizar la bisexualidad como identidad y como narrativa, en pos de una tarea epistemológica que comprenda aquello que "siempre existió", pero invisibilizado. En este punto, recoge antecedentes en los discursos del arte, como el cine y la literatura, y también en el ámbito científico. Es en ese sentido que construye y deconstruye genealogías, definiciones, límites y barreras. Así, la idea de lo liminar y la frontera recorren los diversos textos.

En el prólogo, María Luisa Peralta afirma que “toda frontera que se crea bien delimitada va acompañada de su policía de fronteras" (2018: 11) convirtiéndose en una afirmación que pueda ser crucial como eje de lectura transversal para el libro en su conjunto. Los límites aparecen problematizados en Bisexualidades feministas, describiendo muchas veces subjetividades "tironeadas", presionadas para decidir, definir, elegir entre un espectro dual de la sexualidad, como si la bisexualidad indicara, necesariamente, indecisión e indefinición. Tanto en la sección de los artículos como en las que le siguen, la conceptualización aparece signada por la mirada de lxs otrxs, permitiendo preguntarse por la intervención de los movimientos lesbianos, de las amantes lesbianas, de la vida heterosexual y 
los amantes varones. Específicamente, la adscripción como feministas permite pensar en los modos, en las luchas políticas, que confluyen y se distancian según las necesidades y las construcciones identitarias, y es un recorrido que se traza textualmente, desde la teoría hasta el deseo.

El artículo "Esencias espurias y el continuo bi-torta" pone en escena esta problematización y complejiza afirmaciones que parecen sencillas en una primera mirada. Allí, Mayra Lucio afirma, "Las diferencias entre bisexuales y lesbianas existen, sobre todo cuando hablamos de violencias específicas, pero muchas veces las categorías coexisten en nuestras subjetividades" (2018: 154) proponiendo, por un lado, dar cuenta de las jerarquías establecidas dentro de los colectivos de la diversidad y el maltrato e invisibilización hacia las identidades bisexuales, pero también la posibilidad de generar conocimiento y aprehender la experiencia a través de conceptualizaciones comunes.

Los textos reunidos en "Usar la voz, poner el cuerpo" constituyen una materialización de la posibilidad del cruce, quebrar la dicotomía teoría-activismo que en otros espacios parece inquebrantable y generar una voz social que democratice la experiencia y la información. En esta sección la apuesta voz-cuerpo trae consigo un primer acercamiento a las primeras personas políticas de las Bisexuales Feministas, recogiendo desde la palabra sus vivencias de la militancia. La firma como colectivo de la mayoría de los textos ponen en escena un decir activista que no habla solo por la libertad o el fluir deseante individual, sino que entiende y propone una salida política y colectiva. Como sucede con algunos de los artículos de la primera sección, se incluyen escritos que han sido publicados en otros sitios, específicamente medios de comunicación, muchas veces con intención de denuncia y difusión y que pueden funcionar también como una interpelación a las compañeras del movimiento feminista. El carácter celebratorio y festivo no está ausente -en tanto hay motivos para brindar-, ni tampoco desligado de la potencia transformada de las identidades de la desobediencia. En ese sentido, Laura Arnés declara "nosotras seguimos celebrando porque ni la iglesia, ni el Estado ni la policía nos van a detener: nuestros cuerpos bisexuales y feministas son nuestra revolución" (2018: 182). Pues esa corporalidad que se pone en juego en el espacio público es la misma que desde la experiencia escribe, piensa y genera conocimiento y, además, publica libros.

La última sección, “Poéticas del deseo: relatos desde la experiencia", pone en evidencia y transparenta la subjetividad afectiva de todas las voces que dicen "yo" en estos relatos. Esto no significa que los textos anteriores, incluso los de reconstrucción teórica, no estén enraizados en la propia experiencia vital de quienes escriben y su grupo de pertenencia, pero es en esta ramificación de poéticas donde la vivencia ocupa un lugar primario. Si en la sección anterior se abrían espacio las primeras del plural en una pretensión por documentar lo político, los textos aquí compilados le dan el protagonismo a las primeras voces deseantes. Salidas del clóset "dobles", perspectivas que se amplían, amores que se multiplican, la pregunta por la maternidad y los estereotipos confluyen en la idea de la identidad bisexual como el espacio en el que construir una subjetividad. Luisa Stegmann escribe "si hubiera sabido que existía la bisexualidad, habría podido responderme las preguntas que todavía no podía hacer" (2018: 253) cerrando el libro con la premisa de que la indagación y posterior encuentro de una palabra con la que decirse a sí misma, era un modo de habitar el mundo más ameno y en libertad.

La compilación parece responder, incluso con más interrogantes, a la pregunta que se reformula una y otra vez, a veces como búsqueda y otras como condena: ¿qué se dice cuando se dice bisexualidad? Los argumentos toman diversas direcciones, y algunos textos optan por explicaciones más didácticas y parecen tener una pretensión teórico-pedagógica, mientras que otros interpelan directamente contra los discursos de negación de la bisexualidad - como si pudiera negarse el deseo- haciendo uso de los lugares comunes para desterrarlos, pero también, en virtud de su análisis, por momentos se asume una defensa de las definiciones de propios y ajenos, entre acusaciones de traición, binarismo, puro juego y el "quererlo todo". De este modo, los textos no solo se ocupan y preocupan por sentar las bases para una teoría sobre la bisexualidad, sino que deben encargarse también de desmitificar axiomas desde el prejuicio.

Si no existían modos legitimados de nombrarse, si se apelaba a la falta de información como justificativo para la invisibilización, irrumpe este material como resistencia y en posición de combate hacia los discursos de desconocimiento, odio y ocultamiento que, correctivos, buscan encausar el deseo únicamente entre los polos de lo homosexual y lo heterosexual y proponen una mirada dicotómica y sesgada del deseo y la afectividad. Bisexualidades feministas representa un novedoso aporte al campo de los estudios de género, al pensamiento feminista y a las teorizaciones sobre la sexualidad, pero también configura un horizonte poético a donde ir a buscar experiencias, vivencias y múltiples modos del deseo. Una afirmación se sostiene y perdura a lo largo de todo el libro: la bisexualidad existe, $y$ tiene las puertas abiertas. 